\title{
Natural Radionuclides as Aquatic Tracers in the Terrestrial and the Coastal/Marine Environment
}

\author{
Michael Schubert ${ }^{1, *}$ and Jan Scholten $2, *$ (D) \\ 1 UFZ Helmholtz Centre for Environmental Research, Permoserstr. 15, 04318 Leipzig, Germany \\ 2 Institute of Geosciences, University Kiel, Otto-Hahn-Platz 1, 24118 Kiel, Germany \\ * Correspondence: michael.schubert@ufz.de (M.S.); jan.scholten@ifg.uni-kiel.de (J.S.)
}

check for updates

Citation: Schubert, M.; Scholten, J. Natural Radionuclides as Aquatic Tracers in the Terrestrial and the Coastal/Marine Environment. Water 2021, 13, 742. https://doi.org/ 10.3390/w13050742

Received: 5 March 2021

Accepted: 6 March 2021

Published: 9 March 2021

Publisher's Note: MDPI stays neutral with regard to jurisdictional claims in published maps and institutional affiliations.

Copyright: (c) 2021 by the authors. Licensee MDPI, Basel, Switzerland. This article is an open access article distributed under the terms and conditions of the Creative Commons Attribution (CC BY) license (https:/ / creativecommons.org/licenses/by/ $4.0 /)$.
Investigations in hydrology and hydrogeology are often hampered by a lack of parameters that permit direct observation or monitoring of the processes of interest. Prominent examples of such processes are: (i) groundwater migration; (ii) surface water/groundwater interaction; and (iii) the transport of dissolved contaminants in the aquifer. Powerful tools for indirect process monitoring are the aquatic tracers. Their use generally results in datasets that allow an integrative assessment of the investigated processes, including their driving forces and resulting effects.

Of particular interest in this regard are "Environmental Tracers", defined as ubiquitously occurring natural or anthropogenic substances that are present in all natural waters and can be assigned to distinct sources. In contrast to injected (i.e., artificial) tracers, environmental tracers have three key advantages: (i) they involve no risk of environmental contamination; (ii) they involve no perturbation of the hydrological system being studied, and (iii) they are suited to large-scale and/or long-term studies.

Water-soluble radioisotopes, when used as environmental tracers, have been shown to provide valuable information for a comprehensive understanding of hydrological and hydrogeological processes. Generally, they have the advantage that their activity concentration in any ground- or surface water body changes as a distinct function of time that is defined by their individual half-life. Hence, aqueous activity concentrations in water samples can, for example, be used as indicators for groundwater or surface water residence times.

Two general concepts can be distinguished in this context of using natural radionuclides as aquatic tracers: (i) the radionuclide enters the water body with a certain timeconstant concentration or distinct concentration input function and decays in this new environment (where it is not supported any longer by the decay of its parent nuclide) with time; (ii) the radionuclide concentration in the water of concern starts at zero and builds up with time in the new environment due to the decay of the respective parent nuclide present there (Figure 1).

Both concepts are based on the general decay law, which sets the activity concentration that develops with time $\left(C_{t}\right)$ in relation to the input concentration $\left(C_{0}\right)$ as a function of the elapsed time $(t)$ and the nuclide-specific decay constant $(\lambda)$ (Equation (1)).

$$
C_{t}=C_{0} \times e^{-\lambda t}
$$

Generally, a key criterion for selecting the most suitable natural radionuclide for any specific purpose is its half-life. The half-life should be in the same range as the investigated process. If, for example, the groundwater residence time (the time it takes of a parcel of water to leave a water body) of an aquifer domain or a lake is to be investigated, the half-life of the chosen radiotracer should be comparable with the residence time that is expected for the water body. Thus, rather long-lived radionuclides (such as ${ }^{3} \mathrm{H},{ }^{14} \mathrm{C},{ }^{36} \mathrm{Cl},{ }^{39} \mathrm{Ar}$, ${ }^{81} \mathrm{Kr}$, and ${ }^{85} \mathrm{Kr}$ ) are generally suitable for investigating high groundwater ages. Numerous studies have been published that aimed to investigate aquifer systems with water residence 
times between 10 and $10^{6}$ years. Published radiotracer-based investigations that focus on sub-yearly groundwater residence times are rather scarce in comparison. This is because only a few of the ubiquitously occurring radionuclides show a half-life short enough for covering the sub-yearly timeframe (such as ${ }^{222} \mathrm{Rn}$, the radium species ${ }^{224} \mathrm{Ra}$ and ${ }^{223} \mathrm{Ra},{ }^{7} \mathrm{Be}$, and ${ }^{35} \mathrm{~S}$ ). Figure 2 displays naturally occurring radionuclides that can be applied as age tracers (for dating sediments, soils, groundwater, or surface water bodies) plotted versus the approximately covered age ranges.

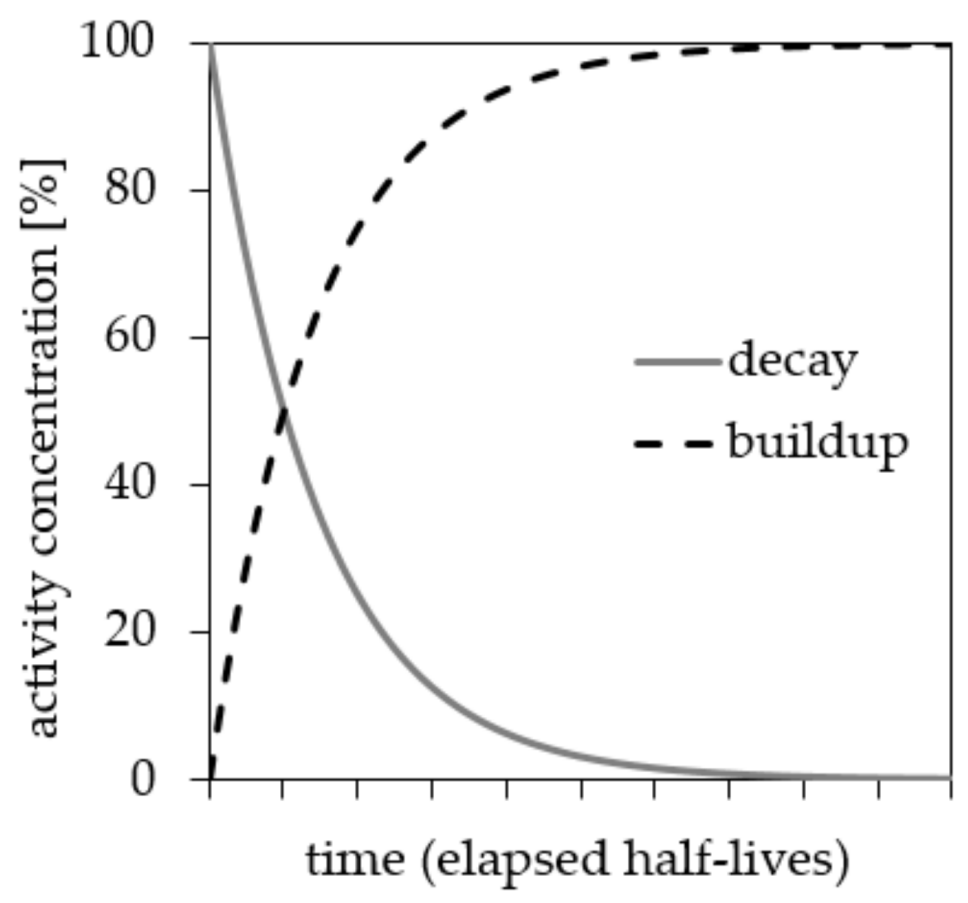

Figure 1. Decay and buildup of radionuclide activity concentrations as function of time.

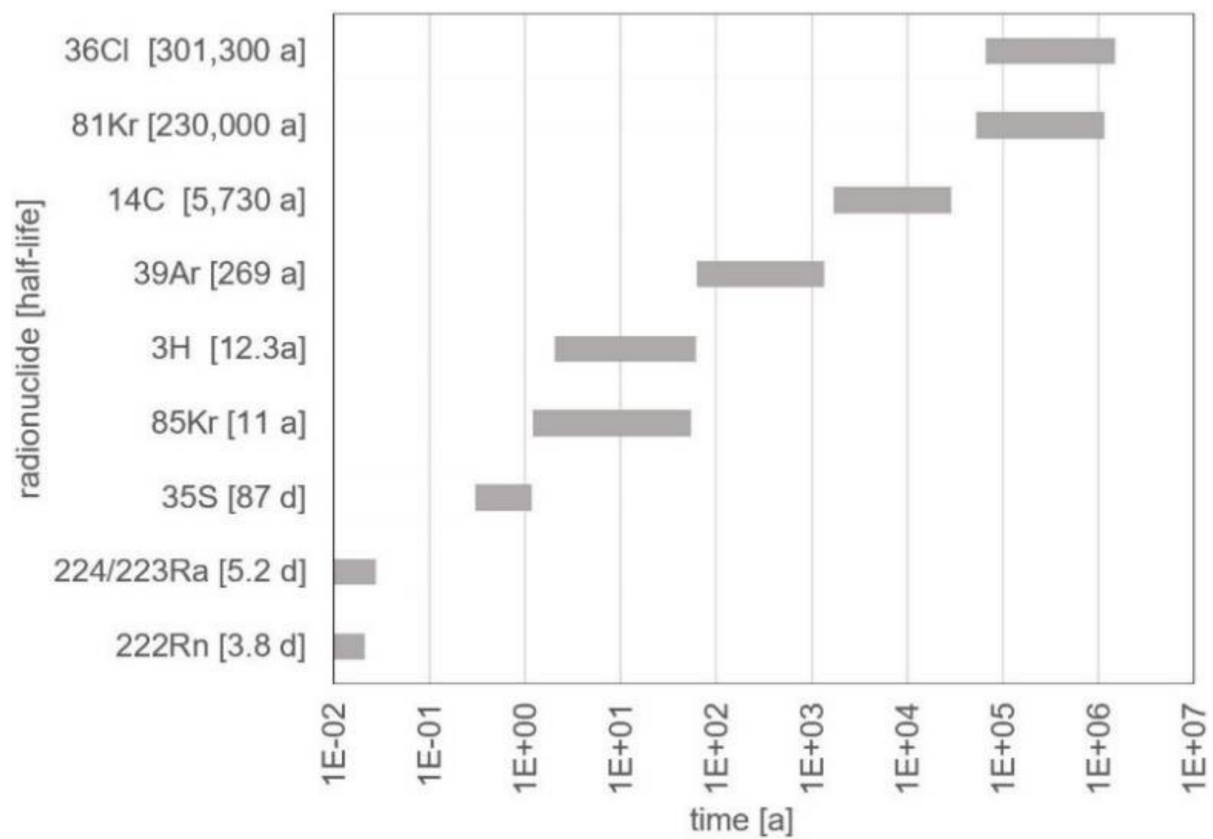

Figure 2. Radionuclides suitable as age tracers versus approximately covered age ranges. 
The aim of this Water Special Issue is to present and discuss innovative approaches that apply ubiquitously occurring natural radioisotopes as environmental tracers in hydrology or hydrogeology. Studies on theoretical aspects relevant to methodical approaches for using naturally occurring radioisotopes as tracers, as well as field studies focusing on their practical application in the terrestrial and the coastal environment, are presented. The range of presented practical on-site applications is wide, including water migration and surface water/groundwater interaction studies, as well as investigations of aquifer contamination. The methodical papers focus on the use of short-lived radionuclides ${ }^{220} \mathrm{Rn}$ and ${ }^{35} \mathrm{~S}$, respectively).

A number of contributions to this Special Issue add specifically to the growing body of literature on submarine groundwater discharge. Luo et al. [1] show, based on radon time-series measurements, that submarine groundwater discharge rates to the Jiaozhou Bay (China) are 8-14 times higher than those of the local rivers. By combining radium isotopes, radon, and stable isotopes of nitrate, Knapp et al. [2] reveal the importance of submarine groundwater discharge for the primary productivity of coastal waters off Saipan (Northern Mariana Island, US). Seasonal as well as tidal variations of radon and radium isotopes, combined with stable isotopes of oxygen and hydrogen of water, recorded at Gaomei Wetland (Taiwan), are related to variable submarine groundwater freshwater fractions and tidal pumping processes by Hsu et al. [3].

Groundwater/river interactions are the focus of two studies by Schubert et al. [4,5] In one of the papers, the problems of radon degassing and radon groundwater endmember estimation, aiming at groundwater discharge localization and quantification, are discussed based on data collected at a small and turbulent stream. The second paper discusses groundwater discharge localization and quantification along a section of the Elbe River (Germany). Here, Schubert et al. use a combination of an integrated radon sampling approach and data processing using the FINIFLUX model. The approach allowed them to differentiate between gaining and losing river sections and to quantify groundwater inflow to the river.

The investigation of water contamination by means of tracer approaches is discussed in two papers of the Special Issue. Mattia et al. [6] present the results of a study that uses an innovative approach to identify groundwater contamination with non-aqueous phase liquids (NAPLs) based on local ${ }^{222} \mathrm{Rn}$ deficit patterns in the groundwater body. The approach uses the very high solubility of ${ }^{222} \mathrm{Rn}$ in NAPLs compared with water. In the paper by Förster et al. [7], stable isotopes of oxygen and hydrogen are used to quantify a so far unknown groundwater-borne phosphorous flux to an artificial lake in Northern Germany. The results of the study are of high relevance for the local water managers, as elevated phosphorous concentrations (i.e., contamination) are responsible for the poor ecological status of the lake. Even though the tracers applied in this study did not include radioisotopes, it was decided to include the study in the Special Issue because of the interesting water-related challenge that was tackled using stable isotope tracers.

Besides these practical on-site studies, the Special Issue contains also two methodical papers. A new tracer approach for estimating sub-yearly groundwater residence time is subject of the paper by Schubert et al. [8]. The authors discuss the use of cosmogenic radiosulfur $\left({ }^{35} \mathrm{~S}\right)$ as short-term tracer and point out that determining the input function of radiosulfur is a main challenge for the application of this tracer. In the second methodical paper, Derek and Schubert [9] present an analytical approach to quantifying thoron $\left({ }^{220} \mathrm{Rn}\right.$, $\left.\mathrm{t} \frac{1}{2}=55.6 \mathrm{~s}\right)$ in water. Because of its short half-life, thoron is difficult to detect in the environment. The innovative method described in this review paper offers the possibility for a very localized identification of groundwater discharge hot spots, as well as for localizing radium-bearing scales inside oil/gas pipelines or domestic water distribution networks.

We want to thank all the authors for their contributions to the Special Issue. We also appreciate the efforts of both the Water editors and the publication team at MDPI, as well 
as the many anonymous reviewers. Finally, we hope that the Special Issue arouses the interest of the esteemed readers.

Author Contributions: The two authors made equal contributions to this editorial. All authors have read and agreed to the published version of the manuscript.

Funding: This research received no external funding.

Institutional Review Board Statement: Not applicable.

Informed Consent Statement: Not applicable.

Data Availability Statement: The data presented in this study (Figures 1 and 2) are available on request from the corresponding author. Besides, the data are publicly available since they are textbook knowledge and shown here only for the purpose to illustrate the general statements given.

Conflicts of Interest: The authors declare no conflict of interest.

\section{References}

1. Luo, M.; Zhang, Y.; Li, H.; Wang, X.; Xiao, K. Submarine groundwater discharge in a coastal bay: Evidence from radon investigations. Water 2020, 12, 2552. [CrossRef]

2. Knapp, M.A.; Geeraert, N.; Kim, K.; Knee, K.L. Submarine Groundwater Discharge (SGD) to coastal waters of Saipan (Commonwealth of the Northern Mariana Islands, USA): Implications for nitrogen sources, transport and ecological effects. Water 2020, 12, 3029. [CrossRef]

3. Hsu, F.-H.; Su, C.-C.; Wang, P.-L.; Lin, I.-T. Temporal variations of submarine groundwater discharge into a tide-dominated coastal wetland (Gaomei Wetland, Western Taiwan) indicated by radon and radium isotopes. Water 2020, 12, 1806. [CrossRef]

4. Schubert, M.; Knoeller, K.; Mueller, C.; Gilfedder, B. Investigating river water/groundwater interaction along a rivulet section by ${ }^{222}$ Rn mass balancing. Water 2020, 12, 3027. [CrossRef]

5. Schubert, M.; Siebert, C.; Knoeller, K.; Roediger, T.; Schmidt, A.; Gilfedder, B. Investigating groundwater discharge into a major river under low flow conditions based on a radon mass balance supported by tritium data. Water 2020, 12, 2838. [CrossRef]

6. Mattia, M.; Tuccimei, P.; Soligo, M.; Carusi, C. Radon as a natural tracer for monitoring NAPL groundwater contamination. Water 2020, 12, 3327. [CrossRef]

7. Förster, W.; Scholten, J.C.; Schubert, M.; Knoeller, K.; Classen, N.; Lechelt, M.; Richard, J.-H.; Rohweder, U.; Zunker, I.; Wanner, S.C. Phosphorous supply to a eutrophic artificial lake: Sedimentary versus groundwater sources. Water 2021, 13, 563. [CrossRef]

8. Schubert, M.; Knöller, K.; Tegen, I.; Terzi, L. Variability of Cosmogenic ${ }^{35} \mathrm{~S}$ in Rain-Resulting implications for the use of radiosulfur as natural groundwater residence time tracer. Water 2020, 12, 2953. [CrossRef]

9. Lane-Smith, D.; Schubert, M. Absolute measurement of thoron in surface waters. Water 2020, 12, 3083. [CrossRef] 